\title{
Evolution of Sheng during the Last Decade
}

\section{Aurélia Ferrari}

\section{(2) OpenEdition}

\section{Journals}

Electronic version

URL: https://journals.openedition.org/eastafrica/340

DOI: 10.4000/eastafrica.340

ISSN: 2790-1076

\section{Publisher}

IFRA - Institut Français de Recherche en Afrique

\section{Printed version}

Date of publication: 1 September 2014

Number of pages: 29-54

ISSN: 2071-7245

\section{Electronic reference}

Aurélia Ferrari, "Evolution of Sheng during the Last Decade", Les Cahiers d'Afrique de l'Est / The East

African Review [Online], 49 | 2014, Online since 07 May 2019, connection on 09 December 2021. URL: http://journals.openedition.org/eastafrica/340 ; DOI: https://doi.org/10.4000/eastafrica.340 


\title{
Evolution of Sheng during the Last Decade
}

\author{
Aurélia Ferrari
}

\section{Introduction}

Sheng, popularly defined as an acronym for "Swahili-English slang" (Mazrui, 1995), emerged in the 1960s in the multicultural environment of Nairobi. It is an urban language which combines mainly Kiswahili and English but also other Kenyan languages such as Kikuyu, Luyha, Dholuo and Kikamba. Sheng is characterized by an important linguistic flexibility. It does not have an official status even if it is widely spoken, especially by the youth. Originally used as a vehicular language between people from different regions, it is becoming a vernacular language, some people born in the 1980s or later having Sheng as their first language. Sheng is not a unique linguistic phenomenon in Africa. In the last fifty years, urbanization and globalization have prompted the emergence of new urban linguistic codes. Such codes are based on multilingual speech and characterized by unstable vocabulary. Many of these varieties derived from a criminal slang to a youth code. Despite constant devaluation by educationalists, traditionalists, language planners and the elites, those youth languages have expanded and transformed into urban varieties that feature highly in popular culture and the media. This is the case for Nouchi (a mixed code made of French and local languages spoken in Abidjan), Tsotsitaal/ Isicamtho (Johannesburg), Hindubill (in Kinshasa, mainly made of Lingala and French), and others. Beck (2010: 12) affirms about African urban languages that:

These "languages," whose linguistic and language-sociological status is still largely unsettled, initially caused a stir among language guardians and educational politicians who were concerned about cultural decay and language loss in the population. This attitude has left its mark on some of the earlier scholarly literature on the topic. Today, however, linguistics is rather interested in the exceptional acceleration of language change, and in the question of whether language birth can be witnessed in contemporary Africa. After all, linguistic creativity and rapid change, and the resulting ephemeral character of vocabulary, are distinctive features of youth languages as a special type of urban language.

If African urban languages have some common features, they all have their own specificities, as argued by McLaughlin (2009: 2). 
[A]lthough there are some generalizations that can be made about the languages of urban Africa $[, \ldots]$ each city is unique, and the particular linguistic outcome is the result of a complex variety of factors, including the ethnic and linguistic make-up of the city, the history and pattern of urbanization, the legacy of colonial policies, and numerous other factors.

This paper focuses on the evolution of linguistic characteristics of Sheng as well as languages practices and attitudes in Nairobi during the last decade. It is based on a comparison between data collected in 2002-2003 for my $\mathrm{PhD}$ thesis and recent data collected during a fieldwork conducted in 2013. ${ }^{1}$ It also discusses artistic uses of Sheng in literature, hip-hop music, cinema and mchongwano as Sheng is part of today's popular culture in Nairobi.

\section{Overview of recent works}

Sheng has attracted increasing attention internationally within academia. Whereas before the last decade, research focused on lexical characteristics and categorization of Sheng, new kind of approaches appeared recently consist of sophisticated linguistic descriptions of Sheng. Examples of such new works on Sheng are:

- The PhD thesis by Philip Rudd (2008) describes the morpho-syntax of Sheng. The purpose of the dissertation - to determine whether Sheng is a mixed language - can surely be discussed and challenged given that all language result from language contacts and therefore have a mixed linguistic structure. However, interesting sociological questions are addressed, like the contribution of Sheng to the formation of a new identity among its speakers.

- The PhD thesis by Mokaya Bosire (2009) on the phonology, morphology, and social profile of Sheng provides a well-documented description with recent data.

The attitude of scholars towards Sheng in relation to its categorization and its impact on urban society is also a notable evolution. Sheng used to be blamed to spoil "pure" languages such as English, Swahili and other Kenyan languages and to have negative impacts on Swahili learning in schools. Nowadays, however, Sheng is considered to be part of linguistic national identity and to neutralize ethnicity (Githiora, 2013). It is categorized as a Swahili dialect or youth language. While former research works paid

1 I wish to thank the French Institute for Research in Africa (IFRA) for their support in conducting fieldwork in summer 2013. 
attention to extreme registers of Sheng, the category of Sheng now encompasses all the mixed codes spoken in Nairobi based on Swahili structure and characterized by common features. New questions also emerged with regard to education. Teachers' training are about to be organized to enable teachers to deal with Sheng and the possibility to include Sheng in the educational system is under consideration (Githinji, 2013) on the ground that, as scholars have shown, the use of the mother tongue (or first language) is beneficial to any learning process and to obtain improved education basics.

Research is also conducted on specific themes such as the use of Sheng and code switching in advertisements, as discussed by Mutonya (2008):

The adaptations in the language of advertising are driven by social and linguistic realities in the city and largely motivated by the marketers desire to reach a broad audience. More significantly, is the realization that HIV/AIDS awareness ads are acknowledging the sensibilities of local culture, with slang helping society save-face while engaging the youth in public dialogue on 'taboo' topics.

However, the myth of pure language is still pervasive among scholars and therefore Sheng continues to be seen as a "dangerous or impure" language in certain research works. Momanyi's research (2009) about the negative impacts of Sheng on Kenyan learners at schools illustrates such stand. It suggests that the emergence of Sheng may have to do with lack of clarity in Kenya's language policy. Describing the significance of Kiswahili in national development, the author argues that Sheng is still stigmatized and stigmatizing:

The social stigmatization associated with this code makes most people in Kenya feel uneasy about the code. It has more often than not been associated with touts, drug pushers, hip-hop musicians and school drop outs. In the education circles, the code is gangster slang, a secret code associated with social misfits, is fluid and not easy to understand.

\section{Definition of Sheng used in this paper}

I will use the word Sheng to designate a continuum of different mixed language codes spoken in Nairobi and based on Swahili grammatical structure. However, some people still use the word Sheng to identify Nairobi's slang only and associate the mixed code commonly spoken in Nairobi today to Swahili, also referred to as "Swahili of Nairobi". From a linguistic point of view, however, and as I will try to prove in this paper, those 
different codes - whether slang or Swahili of Nairobi - have common features and a same linguistic structure which is based on Swahili structure but which is also different from the other existing varieties of Swahili. The most specific characteristics of Sheng are the use of diminutive classes 12/13 (KA/TU), the use of - ang intensive derivative verbs, and noun classes reorganization. Therefore, according to this definition, Sheng has different levels of usages: formal, informal, popular and argotic. The formal level of Sheng is recent and still fragile but there are several examples in political discourses, like for instance during election campaigns.

\section{Evolution of Sheng structure}

The main characteristics of Sheng structure as described below have not changed during the last decade.

\section{Phonological characteristics of Sheng}

The Sheng phonological system differs slightly from that of Standard Swahili. The sounds

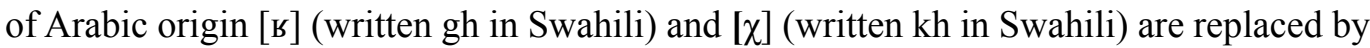
[g] and [k].

The sound $[\mathrm{h}]$ tends to disappear. But as it has a distinctive function in Standard Swahili (there are minimal pairs distinguishing the [h] from the absence of sound), then it is replaced either by adding sound [a] to mark verbal negation of the second person singular (a) either with an additional stress (b).

- Adding the prefix [a] to the affirmative subject prefix in the $2^{\text {nd }}$ person singular in order to negate a verbal form:

Swahili: affirmative: una "you have"

Sheng: affirmative: uko na/ una "you have" negative: huna "you don't have" negative: auko na / auna "you don't have"

- Adding a stress to the affirmative subject prefix (replacing the $h$ ) in order to negate a verbal form.

Swahili: aff.: atakwenda "helshe will go"

Sheng: aff.: ata'enda/ataji toa "he she will go" neg.: hatakwenda "helshe will not go" neg.: 'ata'endal'ataji toa "helshe will not go" 
Table 1: Phonetic system of Sheng consonants

\begin{tabular}{|c|c|c|c|c|c|c|c|}
\hline & Bilabial & labiodental & Dental & alveolar & Post-alveolar & Palatal & Velar \\
\hline Occlusive & $\mathrm{p}$ & & & d & tf & & $\mathrm{k}$ \\
\hline Fricative & & $\mathrm{f}$ & $\theta$ & $\mathrm{Z}$ & f & & \\
\hline Continue & $\mathrm{W}$ & & & 1 & & $\mathrm{~J}$ & \\
\hline Nasal & $\mathrm{m}$ & & & $\mathrm{n}$ & & & $\mathrm{n}$ \\
\hline
\end{tabular}

\section{Morpho-syntactical characteristics of Sheng}

\section{- Noun classes}

Whereas standard Swahili has 16 noun classes as follows: M/WA (1/2), M/MI (3/4), JI/MA (5/6), KI/VI (7/8), N (9/10), U (11:14), KU (15), and PA/KU/MU (16/17/18) according to the common Bantu classification, Sheng has transformed its noun classes system. It is divided between human beings, non-human beings, places and the diminutive noun classes (KA/TU, 12/13). The diminutive classes do not exist in standard Swahili but are used in Sheng as in other Kenyan Bantu languages such as Kikuyu. Therefore we can see that, on the one hand, a kind of simplification occurred given that the 16 noun classes used in Swahili are not used in Sheng, but on the other hand, there are classes in Sheng that are not used in Standard Swahili. This means that speaking of "simplification" is surely not right to define Sheng, as codes used as a first language express in one way or another all the nuances needed in communication. In other words, simplification of certain linguistic aspects always goes along with the creation of other complex structures. 
Table 2 : Sheng noun classes

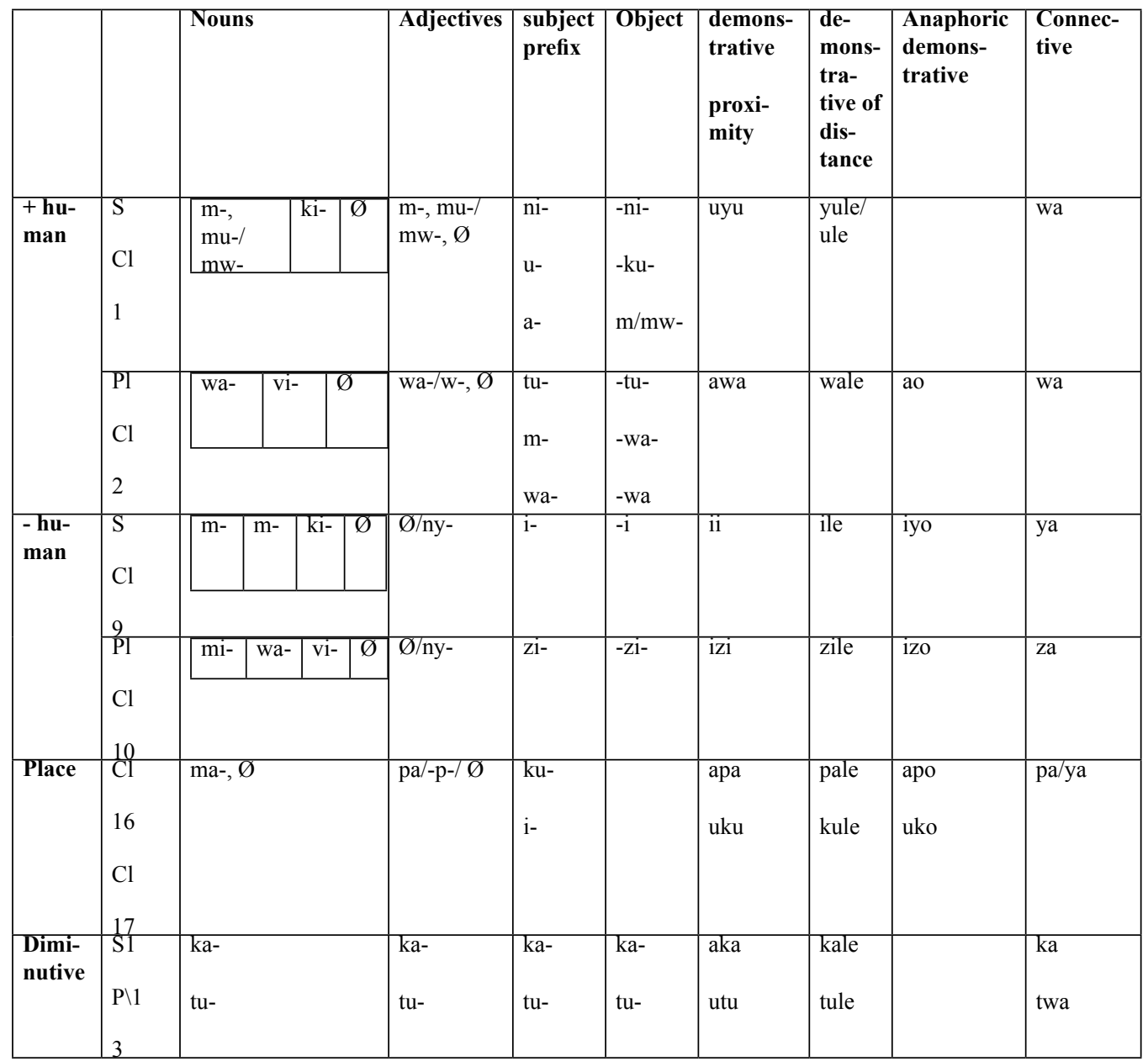

Example in human beings' classes (Sheng): ${ }^{2}$

\begin{tabular}{|l|l|l|}
\hline Awa & mavijana & wanastragal. \\
\hline DEM & PL-youth & SP3P-PRS-struggle \\
\hline
\end{tabular}

Those young boys are struggling.

2 Concerning "wanastragal", I used in my PhD thesis the transcription used here, but Sheng speakers do not use it. They alternate between Swahili and English transcription without specific rules. 
Example in non-human beings' classes (Sheng):

\begin{tabular}{|l|l|l|l|}
\hline Izi & mandizi & ulizibay & wapi? \\
\hline DEM & PL-banana & SP2S-PAST-OBJECT-buy & where \\
\hline
\end{tabular}

Where did you buy these bananas?

Names of animals in Swahili belong to the same class as human beings class (noun classes 1/2) whereas in Sheng, they are classified with non-human beings.

Sheng:

\begin{tabular}{|l|l|l|}
\hline$I i$ & dogi & inadoro. \\
\hline DEM & dog & SP9-PRS-sleep \\
\hline
\end{tabular}

This dog is sleeping.

Swahili:

\begin{tabular}{|l|l|l|}
\hline Mbwa & uyu & amelala. \\
\hline Dog & DEM & SP3S-PP-sleep \\
\hline
\end{tabular}

This dog is sleeping.

Example in locative classes (Sheng):

\begin{tabular}{|l|l|l|l|l|}
\hline Apa & ndani & kuna & moskitoz. & \\
\hline Here & inside & SP17-have & mosquitoes & \\
\hline
\end{tabular}

There are mosquitoes herein.

Swahili uses the KI/VI classes as a diminutive; as a consequence it does not have any specific noun class for diminutive where Sheng used the $\mathrm{ka}-\mathrm{ttu}$ - prefixes.

Sheng:

\begin{tabular}{|l|l|l|l|}
\hline Tebu & cheki & aka & kandai. \\
\hline EXCL & look & DEM & DIM-car \\
\hline
\end{tabular}

Look at this small car. 
Swahili:

\begin{tabular}{|l|l|l|l|}
\hline Hebu & tizama & kigari & hiki. \\
\hline EXCL & look & DIM-car & DEM \\
\hline
\end{tabular}

Look at this small car.

In Sheng, the prefix $k a$ - also serves to express contempt:

Sheng:

\begin{tabular}{|l|l|l|}
\hline Aka & kamsee & kabambi. \\
\hline DEM & DIM-man & DIM-be.not.fun \\
\hline
\end{tabular}

This man is not fun.

$K i$ - is used as angmentative whereas in Swahili $k i$ - is used as a diminutive.

Sheng:

\begin{tabular}{|l|l|l|}
\hline Cheki & iki & kindai. \\
\hline Look_at & DEM & AUGM-car \\
\hline
\end{tabular}

Look at this big vehicle.

In Swahili, the augmentative classes are the JI/MA classes (5/6).

jitu/ a big man/ giant; jiji/ a big city.

It is crucial to stress such differences here between Standard Swahili and Sheng as the use of one prefix can express opposite meanings. For instance, the word kimfuko in Sheng means "a big bag" whereas it means "a small bag" in Standard Swahili.

The marker MA- serves as the generic plural in Sheng.

\begin{tabular}{|l|l|}
\hline Madem & wamejikata. \\
\hline PL-girl & SP3P-RES-go \\
\hline
\end{tabular}

The girls have gone. 


\section{Verbal extensions}

Standard Swahili has several verbal extensions (or derivative verbs) such as: prepositional, passive, stative, reciprocal, causative and reversive. In Sheng, all these verbal extensions are used even with verbs borrowed from other languages (English, Gikuyu...). Another verbal extension called intensive, which is not used in Standard Swahili but appears in other Bantu languages, is used in Sheng as the habitual form. It can be used with the different tense markers (present, future, and past tenses markers) and with the prefix $u$ - (from $h u$ - prefix that expresses habitual actions in Swahili).

\section{(a)}

\begin{tabular}{|l|l|l|l|}
\hline Ye & uendanga & ushago. & \\
\hline $\mathrm{He}$ & HAB-go-INT & countryside & \\
\hline
\end{tabular}

(b)

\begin{tabular}{|l|l|l|}
\hline $\mathrm{Ye}$ & anaendanga & ushago. \\
\hline $\mathrm{He}$ & SP3S-PRS-go.INT & countryside \\
\hline
\end{tabular}

$\mathrm{He} / \mathrm{she}$ is going very often to the countryside.

This verbal extension has also extended uses. According to Rudd (2008), "the aerial feature imperfective suffix $-a(n) g$ is preferred $68 \%$ of the time".

Other observations can be done concerning morpho-syntactical differences between Standard Swahili and Sheng, such as:

- The less often uses of object infixes and locative suffix $n i$-.

$\begin{array}{lll}\text { Swahili: } & \text { nipo nyumbani } & \text { "I'm at home" } \\ \text { Sheng: } & \text { niko hom or niko kwa keja } & \text { "I'm at home" }\end{array}$

- The non-appearance of relative affixes on the verb

- The generalization of "a" as the subject prefix of the 3rd person singular, for example in "he is" (locative): ako in Sheng but yuko in Swahili. 


\section{Lexical characteristics of Sheng}

Lexical characteristics of Sheng have been extensively studied. In fact, most researches concerning Sheng focused on lexical creativity. Only few examples are given here.

- Suffix "o" used with English words

\begin{tabular}{|l|l|}
\hline Sheng word & derived from the word: \\
\hline prifo & prefect \\
\hline jako & jacket \\
\hline filo & film \\
\hline steto & state \\
\hline chipo & chips \\
\hline
\end{tabular}

- Suffix and prefix "o" added to Swahili words

\begin{tabular}{|l|l|l|}
\hline Sheng word & Swahili word & translation \\
\hline obaro & barabara & road \\
\hline odajo & daraja & bridge \\
\hline orezo & rais & president \\
\hline owanjo & uwanja & field \\
\hline odiro & dirisha & window \\
\hline oembo & embe & mango \\
\hline oduko & duka & shop \\
\hline ojijo & kijiji & village \\
\hline
\end{tabular}

- Inversion of syllabes as in French slang called "verlan":

$\begin{array}{ll}\text { "take" } & \text { chukua }>\text { kuachu } \\ \text { "in front" } & \text { mbele }>\text { lembe } \\ \text { "say" } & \text { sema }>\text { mase } \\ \text { "very" } & \text { sana }>\text { nasa } \\ \text { "behind" } & \text { nyuma }>\text { manyu } \\ \text { "house" } & \text { nyumba }>\text { mbanyu }\end{array}$

Other lexical manipulations are used such as idiophones (pumpum for "big, fat", twa twa for "gun"), extension of meaning (tembe means in Swahili "pills" and in Sheng "drugs"), antonym (mzee means in Swahili "old man" but its variant in Sheng msee means "young man"), vibaya means in Swahili "very bad" but "very well" in Sheng), truncation (skiza, from the Swahili word sikiliza, "listen") (Bosire, 2009).

From a linguistic point of view, Sheng has not much evolved in ten years' time. Its linguistic structure and word creation processes are still the same even if new words have appeared such as: memba for "friend", mbegu for "bullet", chafi for "to hide", or gathemba for "father". In addition, some words such as the verb $d u$ for "to do" which were not often used ten years ago are now part of Sheng commonly shared vocabulary. 


\section{Linguistic practices and attitudes in Nairobi}

The research on attitudes toward Sheng completed in 2004 for my $\mathrm{PhD}$ was done mainly in the areas of South B, Mukuru slums and Dandora in Nairobi. It pointed out that Sheng was seen positively in poor urban areas by almost all generations but not among the middle classes and upper classes. However, to the question, "Do you think that Sheng can be standardized in the next decades and becomes a national language?", almost all of the interviewees answered "No", and some young people added that it should not be standardized. Considering the code as a street language, they did not want Sheng to be institutionalized as, through such process, it may be "stolen" from them.

More generally, there are diverse opinions toward Sheng code. The Sheng enthusiasts argue that it is important for youth communication because it breaks down ethnic barriers. Sheng opponents bemoan the loss of pure languages, complain about Sheng unintelligibility by the non-initiated and harshly criticize its negative impacts with school learning.

The contrast between real-life linguistic practices and discourses is, however, very significant. On the one hand, some people devalue this code in their epilinguistic discourses, but on the other hand, they show that they value it through their practice of Sheng in daily life situations, and some even transmit Sheng to their children as a first language, especially in slum areas but not only.

Kenyan radio stations and TV channels have given more space to Sheng during the last decade. Specific programs use it in TV series like Machachari (Citizen TV), Vioja mahakamani (Citizen TV), or Inspekta Mwala (Citizen TV); in comic shows like Churchill show (NTV), Hapa kule news (KTN); and in music or dance programs such as Sakata (Citizen TV), Orange beat ya street (NTV)... Many of these programs switch between English, Sheng, and Swahili. A recently founded radio station called Ghetto Radio (89.5FM or www.ghettoradio.co.ke) advertises itself as the official Sheng station and broadcasts programs in Sheng only.

Nevertheless, even if Sheng is widely used in Kenyan media, it is still restricted to specific programs. For instance, Sheng is not used in official news either on TV radios or on newspapers whereas some African urban languages in other African countries are used for this purpose. For instance in Lubumbashi, news on radio stations and TV channels are broadcast in the mixed code French/Swahili called "Swahili Facile" (Easy Swahili). 
In Kinshasa, the mixed code Lingala/French is used in everyday news. Such level of recognition seems far ahead in the case of Nairobi due to pervasive negative linguistic attitudes and language policies.

In 2006, The Standard newspaper had an issue with the Kenyan Publishers Association (KPA). Indeed, during one of its book exhibition, KPA declared that it will soon publish books in Sheng (Standard 29/9/2006; Momanyi: 2009: 134). However, up to now, the Well Told Story Company is the only publishing group that publishes a booklet in Sheng called Shujaaz.FM (Shujaaz is a Sheng word derived from the Swahili word shujaa which means 'hero', the plural marker [z] has been suffixed to this word; it is a grammatical process used in Sheng which has been borrowed from English) every first Saturday of the month, available in The Nation newspaper. It is one of the very few examples of Sheng publications. Shujaaz.FM is a monthly comic book written in Sheng that was launched in February 2010 and it has reached now 43 editions. Shujaaz.FM is a focused national communication effort, which has the purpose to empower young Kenyans with information, ideas, and motivation to become active participants in community development. The main story is about a boy called Boyie who left school in 2009. Boyie is jobless and does not have a place in higher education. Like most of his friends, he is facing an uncertain future. However, he has a talent for electronics. Therefore, he builds himself a FM pirate radio station in his bedroom. Moreover, from his bedroom he is able to hack into various FM stations and broadcast a radio show every day under his pen name DJ B. His show is called Shujaaz.FM. Boyie uses his show to talk to the youth, notably to implore them to take steps to improve their lives. He invites them to share ideas that have helped them in some way and passes them on around Kenya. ${ }^{3}$

In addition to stories and comic strips, you can find in the small book Shujaaz.FM:

- New Sheng words with their translations: Gathemba "father"; chuste "girl"; jura xana "a very foolish person"; kao "come"... (Shujaaz, 6 July 2013)

- Mchongoano (see 3.1 below)

- Shujaaz even proposes its readers to send them SMS if they do not understand some Sheng words ("Kama kuna majna za Sheng huelewi, tuma SMS")

- Shujaaz has also educational purpose - see for instance Shujaaz, 6 July 2013 where the importance of composts and processes to make it were explained.

3 Source : http://shujaaz.fm/ 
Another example of written uses of Sheng is its uses in adverts. It is now a common phenomenon especially when the product is concerned with youth issues:

Adverts for condoms: Nakufeel "I feel you."

Adverts for mobile operators: Bamba hapa, maliza hapa "top up here" (Safaricom)

Adverts for radio stations: Maisha ni kudunda "life is pulsating" (Maisha FM).

But the written use of Sheng is still a minor phenomenon. There is no literature in Sheng, and even the well-known Kwani? book published by Kwani Trust advertised as the book of the Nairobian youth gives little space to Sheng. For instance, in Kwani? 2 (2004), there are around 15 pages on Dandora life in Sheng ("Maisha kule D: in the words, lyrics, poems" by Mashifta, Don Rawzi, and Mc Kah") among 334 pages in English. In Kwani? 3 (2005), only a short poem ("Zana za vita nashika”) by Kama from Kalamashaka rap band and other poems by authors Mc Kah ("Ukombozi wa ki akili"), Kitu Sewer and G. Wiji. Two pages of SMS also feature as well as an interview and a short story by Mwas written in Sheng. Strangely, or maybe in order to reach a bigger audience, the space given to Sheng has been smaller and smaller. In Kwani? 4 (2007), less than five short poems of mainly Kenyan rap group Ukoo Flani Mau Mau are in Sheng, equivalent to only 4 pages in a book of more than 400 pages. In the last Kwani? 7 (2012) about the Kenyan diaspora, again, only short poems, messages and transcriptions of emails on visa issues are available in Sheng.

\section{Sheng in urban arts}

\section{Sheng in literature}

Some of the contributions in Kwani like poems and stories are part of urban literature written in Sheng. Here we will have a look at one of the poems written by Lenjo Maza that deals on immigration issues (Kwani?, 2012). It shows that Sheng is not only used in Nairobi but also in the Kenyan diaspora in different parts of the world, though it seems to be used in a code-switching speech usually between Sheng and English (for instance, in this poem, there are several examples of code switching between English and Sheng: "Rumors best paying jobs, kazi za mocha"). 


\section{Ideas za Hollywood}

\section{Hollywood ideas}

Nikiwa primo, Father Richard na silver screens

When I was in Primary school, Father Richard and silver screens

$[\ldots]$

Tukaamini majuu a bed of roses, tunapaint wishes

Then we believed that Occident was a bed of roses, we painted/had wishes

kwa ma-applications za visa

for visa application

Believing tutarudi loaded kistyle ya P. Diddy

Believing that we will be back loaded as P. Diddy

Rumors best paying jobs kazi za mocha

Rumors best paying jobs, (in fact) mortuary job

Anything hata dead bodies ku-make hizo dead presidents

Anything, even dead bodies to make dead presidents (US dollars)

Mkwanja kwa head zinamek the world go round

Money in head makes the world go round

Kujipata ndani ya NYC juu ya akala

To find yourself in New York City wearing akala (a sandal made from old car tyres)

Huna idea first step inachukuliwa wapi

You do not have any idea where to take the first step

And by the time umefigure out kusonga lembe

And by the time you have figured out how to go in front

Inakaa "your paper are not in order" juu juu

It seems "your paper are not in order" because

Umeland JKIA bado juu ya akala

You landed at Jomo Kenyatta International Airport with akala. 


\section{Mchongwano}

Mchongoano designates a verbal duel in Sheng somehow comparable to African American ritual insults but slightly less virulent and belonging to a more derisory and comic framework. Githinji (2007: 89) defines it as follows: "Mchongoano is a ritualized genre of verbal duel popular with the Kenya youth where one antagonist insults another or members of his/her family. Though ritualized, the topics involved mark it as a risky discourse that oscillates between verbal play and aggressive slurs depending on the context and social relationship between participants." According to Githinji, the primary function of Mchongoano is socialization. There are several types of mchongoano: informal, formal, face-to-face, mchongoano addressed to no one (internet) and media transfer (politician, singers).

The origin of the word mchongoano is questionable. This term does not exist in Standard Swahili and it is attributed to Sheng language. If the word mchongoano is not recognized as a Swahili word, it may however be coming from the Swahili verb -chongoa that originally means "to sharpen to form a point", and which has been used in a reciprocal form -ana: chongoana "to sharpen each other to form a point" ${ }^{4}$ Therefore, the word mchongoano could mean literally, "the fact of sharpening one another to form a point", less literally identifying mockery, scorn, ritual insults or scoff. However, the word is pronounced with a specific tonal scheme. It could let us think that the word is coming from a tonal language and therefore not from Swahili, or that the tonal scheme is a way to give to this word a Sheng connotation.

The origin of Mchongoano is not well known and is definitely complex, as the influences seem to be multiple. Some attribute it to the black American "soundings'. Soundings are formal trading of ritual insults also called the "dozens" or "signifying". According to Labov (1972: 127), the ways in which sounds are delivered, and the evaluation of them by the group follow a well-established ritual pattern. Sounds are evaluated overtly and immediately by the audience. The mark of winning is laughter. The sounds often rhymed couplets, and they usually involve insults concerning mothers or fathers. If we support the hypothesis that mchongoano comes from dozens then we should not forget that African American culture has African sources and therefore mchongoano is drawn in a circle influence (Africa to America and then back to Africa). A similar example is

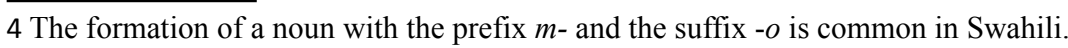


given through hip hop (Ferrari, 2007) where, for instance, Kenyan youth following hip hop movement find themselves and assimilate their culture not as a foreign culture but as a global African culture.

The mchongoano has definitely not only outside influences but also local influences. We can see some similes with the taarab lyrics - a Swahili musical genre of the Kenyan and Tanzanian coast (Askew, 2002) - and Kikuyu traditions that make use of some similar games during circumcision rituals (Githinji, 2007: 98).

In taarab lyrics, the insults between different adversaries and singers are common. One illustration of this can be found in the song Kitumbiri by Jinamizi A. S. and Hatibu Akida, Lucky Star Musical Club (Tanga):

Hata nawe kitumbiri, kitumbiri majaliwa,

Umejifanya hodari miti kutaka nyanyuwa

Hali tawi na tambiri, la kushindwa kupasua

Even you, monkey, favored monkey,

You thought yourself so great, wanting to uproot trees

When you are incapable of breaking branches.

Proverbs in taraab are also used in these ritual insults; hilo ni dua la kuku, juwa halimpati mwewe "Know that the prayer of the chicken does not affect the hawk" (Askew, 2002: 298).

\section{The content of mchongoano}

The linguistic processes used are wordplay/pun and exaggeration. Some mchongoano can be seen as real insults and mockery because it can refer to some particular physical (ex: $1,3,5,6,7,8,10,13,14,15,17)$ or mental aspects of the person (ex: 9, 19). Other can be considered as a denunciation of social inequalities ( ex: 11,18$)$ or society problem (Githinji, 2007: 90).

Mchongoano can be linked with hip hop culture which is rising in Nairobi since 1980 as dual spirit of competition, and the idea of transforming negative thought into form of art such examples as hip hop dances or rap battles. 
Some websites, like www.mchongoano.com, give every week the top ten of the best mchongwano. This illustrates another way to compete through languages.

Examples of mchongoano:

1. Una mkono rough hadi ukishika mouse, computer inadai found new hardware.

Your hand is so rough, if you touch a mouse, computer even claims "found new hardware".

2. Ati wewe ni mchafu mpaka ukiingia kwa lake kuswim, fish zinatoka kutema mate.

You are so dirty, if you go in a lake to swim, fish even get out of the water to spit.

3. Ati wewe ni mzee hadi ukizaliwa "old testament" ilikuwa inaitwa "testament" You are so old, when you was born, the Old Testament was even called "testament"

4. We ni dentist mpro hadi unang'oa blue tooth ya phone yako.

You are so professional dentist; you even pull out blue tooth on your phone

5. Ati wewe mweusi tu sana mpaka hauna bright ideas.

You are so black; you do not even have bright ideas.

6. Ati mtoi wenu alizaliwa akiwa mblack mpaka doki akasema, "Kameungua".

Your child is so black that the doctor said he was burnt.

7. We ni mkonda hadi uki dance helicopter una take off.

You are so slim that when you dance, helicopter takes off.

8. Uko na macho kubwa hadi wewe huitwa eyewitness.

You have such big eyes; you are even called eyewitness.

9. We ni fala hadi ulidial *144\# kucheck balance kwa ATM.

You are so foolish that you dial $* 144 \#$ to check your balance in a ATM machine

10. Manzi yako ni mhairy hadi ako na Afro kwa nipples.

Your girlfriend is so hairy that she has big hair in her nipples.

11. Ati nyinyi ni wadosi mpaka mnapeleka kuku shule.

You are so rich; you even take your chicken to school. 
12. Wee ni mwizi mpaka padlock ikikuona inajifungua

You are such a thief, when the padlock sees you, it even unlocks itself.

13. Wee ni mrefu mpaka giraffe zinacomplain

You are so tall even the giraffes complain.

14. Fathako ni mrefu mpaka akianza kuvaa trouser inapofika waist ishakwisha fashion Your father is so tall that when he begins wearing a pant, by the time it gets to the waist, it has gone out of fashion.

15. Wewe ni mugly hata hauneed mask kuact movie ya horror.

You are so ugly; you do not even need a mask to act in a horror movie.

16. Wee mchafu mpaka mbu ikikuuma, inatema mate kwanza.

You are so dirty that when a mosquito bites you, it first spits.

17. Mbuyu wako mnono mpaka akikalia ashu inakuwa kobole mbili!

Your father is too fat that if he seat on a coin of ten shilling it becomes two coins of 5 shillings.

18. Boss!!! Umesota mpaka, huwezi ku afford ku pay attention.

You are so broke you cannot even afford to pay attention.

19. Wewe ni fala, uligongwa na a parked car.

You are so foolish; you even have been knocked by a parked car.

\section{Sheng in hip hop music}

Sheng performances like hip-hop music described here as an artistic uses of Sheng constitute also a spreading dynamic of this code. The young Africans in urban areas are caught between the Western way of life led in the big towns and values considered more African. Sheng is a way to combine them.

In the song Angalia saa by Mau Mau, the topic of the song is the Kikuyu struggle for independence and the valorization of Kikuyu heroes (e.g. Shege wa Kifiro, Muthoni Nyanjiru, Kimathi) but the language used is Sheng and not Kikuyu. This proves the importance of Sheng even among the conservative youth often associated to the Mungiki political radical movement. 
Damu jasho machozi

Blood, sweat and tears

Mau Mau wakashinda war mashabiki wakaenda na trophy

It is Mau Mau who won the war, the spectators went with the trophy

Matigari hana ata ka-ploti

The Mau Mau survivor doesn't even have a piece of land

Serikali inataka imfukuze Nairobi

The government wants to evict him from Nairobi

Magava wanataka wamangishe jirongi

The government wants to shoot him

Hawana kopi

They don't have information

They don know who we be

They don't know anything about us

Haikosi

Of course

White highlands no more

Si siri hawatoshi

It's not a secret, and it's not enough

Hii vita imepita rangi ya ngozi

This war has overstepped the color of skin.

Na kabila najua ni mbili tu

And I know that there are only two tribes

Maskini na mdosi

The poor and the rich

Synchronayzini taym tu o fayv

Synchronizing time 2005

Decolonayzini mayndz

Decolonizing minds

Msiseme mliji-hypnotise na rhyms

Don't say that you was hypnotized with rhymes

Visions za Shege wa kifiro

Visions of Shege wa Kifiro

Bugi mato 
They have bells in their ears

Mtu anatusi matiti ya mother alinyonya

A man disrespects his mother (literally, a man insults her mother's chest that he has sucked)

Alafu anapigiwa makofi za kilo

And people applauded a lot

Wa-shoot Muthoni wa Nyanjiru

They shoot Muthoni Nyanjiru

The same route wa-rape mama yetu Njeri

The same thing happen to our mother Njeri who was rapped

Ivo ndivo wana-treat ma-hero

It's how they treat heroes

Ka Kenya ni matrix nani ndio Neo

If Kenya is Matrix, who is Neo?

Ka Kimathi hakuwa the one

If Kimathi wasn't the one

Then society iko drunk na opium

Then the society is drunk with opium

Also, in the song Shuhudia by Kah that speaks about division between African states, the language used to represent the ideology of Pan-Africanism is still Sheng.

\section{Mipaka kila mahali}

Boundaries everywhere

Mipaka bila maswali

Boundaries without questions

Tume gawinyika hali

Separation of situation

[...]

Wazee vijana kusikilizana noma sana

Young and old coming to a consensus is very difficult

Mipaka za kifamilia

Family boundaries 


\section{Mipaka za ki jiografia}

Geographical boundaries

Kutudividia dunia, kufikia, Kenya,Tanzania

They have divided our world, to reach Kenya, Tanzania

Nigeria list inaendelea

Nigeria, the list keeps going on

Sheria zina letwa na viongozi waking'agania power

Laws are being creates by politicians who are after power

Nania ya kutojivunia,nchi ya wafalme weusi

Without any intent of gaining anything in the land of black kings

Ma heathens ma puppet masters wanatumia

The heathens and the puppet masters they are using

Uchumi kuvutia marionettes inabakia

Economy to attract marionettes, it remains

Soul ya Africa inauzwa kwa price ya diamonds

African soul is being sold for the price of diamonds

\section{Sheng in cinema}

Nairobi HalfLife is a Kenyan drama film of 2012 mostly in Sheng directed by David Tosh. It is the first movie that fully resorts to this code. The story is about a young aspiring actor named Mwas who moves from his home village to Nairobi to try to make money and realize his dreams in life. As a Kikuyu speaker, he needs to learn Sheng quickly in order to live in Nairobi. But as he tries to adapt to his new life and looks for auditions in a theater, he finds himself integrated into a street gang of young thugs. The story starts in Kikuyu in his native village then switch to Sheng in Nairobi streets and English in auditions and rehearsals of plays.

Mwas: Ah Oti Gota jo mtu wangu

Ah Oti give me five, my man!

Oti: We ni job gani unadu?

Which kind of job are you doing?

Ushabonga na Dingo

Did you talk to Dingo?

Mwas: Hee na akanirusha hii waks 
Yes and he got me this job.

Oti: Hai ni uchokosh, kuja ivi

This is like dumpster diving, let's go.

Mwas: Hay na waks?

What about the work?

Oti: Unaiachanga kimangoto.

Leave it like this.

Mwas: Unamek do wapi?

Where do you make money here?

Oti: Pande zote lakini kiujanjaz tu,

Everywhere but you have to be smart

Unajua gaza ni masper parts

In Gaza, the main moneymaker is spare parts

Through the examples given of some artistic uses of Sheng, Sheng seems to assert itself not only in everyday communications but also in the urban artistic landscape.

\section{Conclusion}

After comparing the data that I collected ten years ago for my $\mathrm{PhD}$ thesis with the set of new data collected in 2013, I can say that, even if urban new languages are known to evolve fast, I have not detected important changes in Sheng, whether on the language structure itself or in its social uses and status. Of course, the 'deep Sheng' has seen its vocabulary changed like other slangs due to its function of secret code but what we call here the common Sheng has remained stable. However, it is undeniable that Sheng is still spreading, and such a spread cannot be stopped. It has become so common in Nairobi everyday communication that a Sheng language manual on CDs called Ultimate Sheng (2013: Banential medi) is now sold in supermarkets. This manual targets foreign residents "to make them aware of what is going on around them" as well as parents "to enable them to bond with their children", corporate marketers "to target the youth better", and politicians "to connect with the youth". Sheng is also spreading outside Kenya through an increasing number of Sheng websites and the significant Kenyan diaspora. Therefore, if Sheng has not really changed during the last decade, its expansion throughout Kenyan society is a central aspect of its development, notably showing that it has not been affected by existing negative attitudes toward this language code. And as history has already 
shown in other countries, negative attitudes can even be a step towards the development of language: French was seen as a deformation of Latin some centuries ago; it has been standardized and grammatized and is now the national language of France widely spoken in France and beyond.

This expansion of Sheng in many areas of Kenya does not affect the coastal region of the country, from Mombasa to Lamu. The Coast gathers a majority of Swahili native speakers whose mastering of "proper" Swahili is strongly tied to their specific coastal identity, hence their being very watchful when it comes to Swahili correctness and correction. This was not the case in Nairobi or other parts of Kenya where Swahili was a vehicular language. It may also be one of the reasons why Swahili of Lubumbashi has been stabilized and described before Sheng (Schicho, 1982): there were no Swahili native speakers in Lubumbashi to correct Swahili. The origin of Sheng is still unknown, some papers asserting that it originated from slang, but we can also affirm by looking at data from Whiteley (1974) that it may also come from different types of code switching.

Categorization of Sheng is still not clear. Indeed, categorization of a language can involve many aspects such as linguistic description, language attitudes, language history, language policies and practices. In the particular case of Sheng, which has now become the mother tongue of many children in the slums areas of Nairobi, we have been able to prove that Sheng has developed its own phonetic, morphological and grammatical system (Ferrari, 2005; Bosire, 2009). I think it is important to place Sheng studies among other African urban languages studies. About categorization, I argue that if the linguistic description of such varieties show that the urban code has reached a stable stage and has an independent linguistic system, therefore those languages should just be classified as new languages, because they do not correspond to others classification such as Creole, pidgin, slang, code switching, etc. We could also describe them as mixed languages, but which language is not mixed? French or English are all mixed languages. So the only specificity of these urban languages is to be new.

Sheng can also be categorized as a Swahili dialect despite the fact that the term Swahili dialect usually refers to old dialects (Kilamu, Kipemba,...) that have not really been influenced by European languages. Therefore, when categorizing Sheng as a Swahili dialect we should specify that it is a 'special' dialect because it appears recently and it incorporates meaningfully linguistic aspects of English ( Ferrari, 2012: 175-180). 
Finally, when we think of the future of African languages facing globalization and the problem of endangered languages, we should also remember that the death of languages is a natural process. Any language has a limited life expectancy. Of course, it is very important to describe endangered languages before their death for the purpose of history, cultural and linguistic aspects but we should take into consideration new urban languages because the study of new urban languages allows a better understanding of modern societies.

\section{Bibliography}

Antoine, Philippe, Jacqueline Billiez, et al. Des langues et des villes (actes du colloque). ACCT Didier Erudition, 1990.

Askew, Kelly. Performing the Nation, Swahili Music and Cultural politics in Tanzania. Chicago and London: The University of Chicago Press, 2002.

Bosire, Mokaya. Sheng: The Phonology, Morphology and Social Profile of an Urban Vernacular. Proquest, Umi Dissertation Publishing, 2011.

Bosire, Mokaya. "What Makes a Sheng Word Unique? Lexical Manipulation in Mixed Languages." In Elected Proceedings of the 39th Annual Conference on African Linguistics, ed. Akinloye Ojo \& Lioba Moshi, 77-85. Somerville, MA: Cascadilla Proceedings Project, 2009.

Caubet, Dominique, Jacqueline Billiez, et al. Parlers jeunes ici et là-bas : Pratiques et représentations. Paris: L'Harmattan, 2004.

Chacha, Leonard. "A Sketch of Kiswahili Comic Discourse in Nairobi." Les Cahiers d'Afrique de l'Est 36 (2007): 1-32.

Ferrari, Aurélia. "Hip Hop in Nairobi: Recognition of an International Movement and the Main Means of Expression for the Urban Youth in Poor Residential Areas." In Songs and Politics in Eastern Africa, Kimani Njogu \& Hervé Maupeu (eds.), 107-128. Dar es Salaam/Nairobi: IFRA \& Mkuki na Nyoka Publishers, 2007.

Ferrari, Aurélia. Emergence d'une langue urbaine: le sheng de Nairobi. Louvain/Paris: Peeters, Collection Afrique et langage, 2012.

Githinji, Peter. "Sheng and language pedagogy." Paper at "Sheng language in Kenya: structure, uses and pedagogy" conference, IFRA, Nairobi, 16 "th July 2013.

Githinji, Peter. 2008, "Ambivalent Attitudes: Perception of Sheng and its Speakers." Nordic Journal of African Studies 17, no. 2 (2008): 113-136. 
Githinji, Peter. 2008, "Sexism and (mis)representation of women in Sheng », Journal of African Cultural Studies », Volume 20, Issue 1, Special Issue: East African Culture, Language And Society, 15-32.

Githinji, Peter. Insults and Folk Humor: Verbal Transgression in Sheng's Mchongoano, 'The joy of Language', Proceedings of a symposium https://www.msu.edu/ dwyer/ JOLIndex.htm

Githinji, Peter. "Mchongoano, Verbal Duels: Risky Discourse and Sociocultural Commentary." In Cultural Production and Social Change in Kenya: Building Bridges, Art Culture and Society, ed. Kimani Njogu \& Oluoch-Olunya, vol.1. Nairobi: Twaweza communications, 2007.

Githinji, Peter. Bazes and Their Shibboleths: Lexical Variation and Sheng Speakers' Identity in Nairobi, Nordic Journal of African studies, 15, no. 4 (2006): 443-472.

Githiora, Chege. "The Rise and Rise of Sheng: Language and Identity in Modern Kenya." Paper at "Sheng language in Kenya: structure, uses and pedagogy" conference, IFRA, Nairobi, 16" July 2013.

Kang'ethe-Iraki, Frederick, Cognitive Efficiency: The Sheng Phenomenon in Kenya, Pragmatics 14, no. 1 (2004): 55-68.

Kouadio N'Guessan, J. "Le nouchi abidjanais, naissance d'un argot ou mode linguistique passagère." In Des langues et des villes (actes du colloque), ed. Philippe Antoine, Jacqueline Billiez, et al, 373-383. ACCT Didier Erudition, 1990.

Lafage, S. "Hybridation et 'français des rues' à Abidjan." In Alternances codiques et français parlé en Afrique, ed. Queffelec, 280-291. Publications de 1'Université de Provence, 1998.

Labov, William. "Rules for ritual insults." In Studies in Social Interaction, ed. D. Sudnow, 120-169. New York: Free Press, 1972.

Mazrui, Ali. "Slang and Code-Switching: the Case of Sheng in Kenya." In Afrikanistische Arbeitspapiere, ed. Rose Marie Beck, Thomas Geider \& Werner Graebner, 168-179. Swahili Forum II, n²42, 1995.

Mc Laughin, Fiona. "Introduction to the Languages of Urban Africa." In The Languages of Urban Africa, ed. Fiona Mc Laughlin, 1-18. London: Continuum, 2009.

Momanyi, Clara. "The effects of Sheng in the Teaching of Kiswahili in Kenyan School." The Journal of Pan-African Studies 2, no. 8 (2009): 127-138.

Mosoti, Edwin. "Taarab or Songs of Abuse? Verbal Duels in East Africa." Muziki: Journal of Music Research in Africa 9 (2012): 13-34.

Mutiga, Jayne. "Effects of Language Spread on a People' Phenomenology: The Case of Sheng' in Kenya." Journal of Language Technology \& Entrepreneurship in Africa 4, no. 1 (2013). 
Mutonya, M. "Swahili Advertising in Nairobi: Innovation and Language Shift." Journal of African Cultural Studies 20, no. 1 (2008): 3-14.

Njogu, Kimani \& G. Oluoch-Olunya. 2007, Cultural Production and Social Change in Kenya: Building Bridges, Art Culture and Society, vol. 1. Nairobi: Twaweza communications, 2007.

Ogechi, Nathan Yori. "Sheng as a Youth Identity Marker: Reality or Misconception?” In Culture, performance \& Identity: Paths of Communication in Kenya, ed. Kimani Njogu, 75-92. Nairobi: Twaweza Communications, 2008.

Rudd, Philip, Sheng: The Mixed Language of Nairobi. Phd Diss., Ball State University, 2008.

Schicho, Walter. Syntax des Swahili von Lubumbashi. Wien: Afro-Pub, 1982.

Wasike, Chris. "Cali, Genge Rap Music and the Anxieties of Living in the Glocalized City of Nairobi." Muziki: Journal of Music Research in Africa, Jua vol. 8 (2011): 18-33.

Whiteley, Wilfred H. Language in Kenya. Nairobi, Oxford University Press, 1974. 